\title{
JOGO DE PONG VIRTUAL CONTROLADO POR MOUSE E CÉLULA DE CARGA DE SISTEMA DE ELETROMIOGRAFIA
}

\author{
L. G. B. Fontes*, M. Borges*, N. M. Policena* e P. A. Borges*. \\ *Faculdade de Engenharia Elétrica, Universidade Federal de Uberlândia, Uberlândia, Brasil. \\ E-mail: pabloassisborges@gmail.com
}

\begin{abstract}
Resumo: O presente projeto visou o desenvolvimento de um serious game de pong virtual, onde os usuários podem controlar o jogo por meio potencial eletromiográfico com auxílio de célula de carga. O objetivo de desenvolver um jogo desta forma é criar mecanismos de fisioterapia para pacientes que necessitam de reabilitação dos membros superiores.
\end{abstract}

Palavras-chave: Jogo, Célula de Carga, Reabilitação

Abstract: This project aimed to develop a serious virtual pong game, where users can control the game by electromyographic potential load-cell help. The goal of developing a game like this is to create mechanisms for physical therapy patients who need rehabilitation of the upper limbs.

Keywords: Game, Load-cell, Rehabilitation

\section{Introdução}

Um "jogo sério" - tradução literal do inglês "serious game", é um software ou hardware desenvolvido por meio dos princípios do design de jogo interativo, com o objetivo de transmitir um conteúdo educacional ou de treinamento ao usuário. O termo "sério" (serious) refere-se que o jogo é voltado mais para fins educacionais do que de entretenimento. Eles têm sido amplamente utilizados nas áreas de defesa, educação, exploração científica, serviços de saúde, gestão de emergência, planejamento urbano, engenharia, religião e política, de uma forma imersiva ou interativa que possam ser usufruídas da melhor forma possível. [1]

Atualmente existem inúmeros trabalhos desenvolvidos com utilização do serious game como um meio de trabalho em reabilitação de atletas ou ainda em casos de fisioterapia para pacientes com graves lesões [2] [3] [4], devido ao crescimento e desenvolvimento das ferramentas de realidade virtual.

Em meados dos anos 2010, a empresa EMG System ${ }^{\circledR}$ desenvolveu o EMG 230 DL [5], que é um sistema de aquisição de sinais biomédicos de 1 à 16 canais, versátil com condicionadores de sinais para transdutores diversos com ou sem conversor analógico digital.

O presente trabalho visou unir as tecnologias do EMG 230 DL com o desenvolvimento de um serious game, que possibilita o exercício e o a medição da força exercida pelos membros superiores. Com isso, desenvolver um game que pode auxiliar á reabilitação de membros superiores durante o processo de fisioterapia.

\section{Materiais e métodos}

Para o desenvolvimento do game, foi utilizado o controlador Arduino DUE, para aquisição do sinal gerado pelo EMG System ${ }^{\circledR}$ com a Célula de Carga.

O EMG 230 DL da EMG System ${ }^{\circledR}$ foi fornecido pela instituição Faculdade de Engenharia Elétrica da Universidade Federal de Uberlândia para fins de desenvolvimento de projetos na área de Engenharia Biomédica.

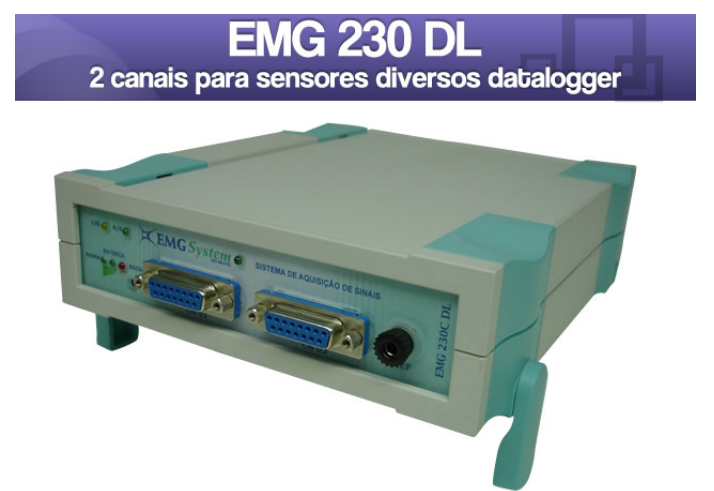

Figura 1 - EMG System ${ }^{\circledR}$ Modelo EMG 230 DL

O método utilizado para realização do projeto fundou-se nos seguintes passos: (1) Revisão Bibliográfica; (2) Montagem do hardware; (3) Planejamento, Desenvolvimento e Implantação do software de controle do sistema; (4) Implantação do sistema; (5) Testes do Protótipo e (6) Finalização.

Em revisão bibliográfica, realizada por veículos de pesquisa como PubMED, Google Acadêmico, e Web of Sciencie, foram levantados diversos serious games com intuito de reabilitação dos membros superiores.

Para desenvolvimento do jogo, foi utilizada a metodologia de desenvolvimento por Modelo Cascata de Produção (PRESSMAN, 2010), que consiste em desenvolvimento por etapas seqüenciais, onde uma depende da outra [6]. O fluxograma do processo de desenvolvimento pode ser verificado na Figura 2. Por sequência, as etapas foram: (1) Requisitos do Sistema, (2) Requisitos do Software, (3) Design do Software, (4) Codificação, (5) Teste, e por fim (6) Lançamento/Implantação. 
tratamentos fisioterápicos.

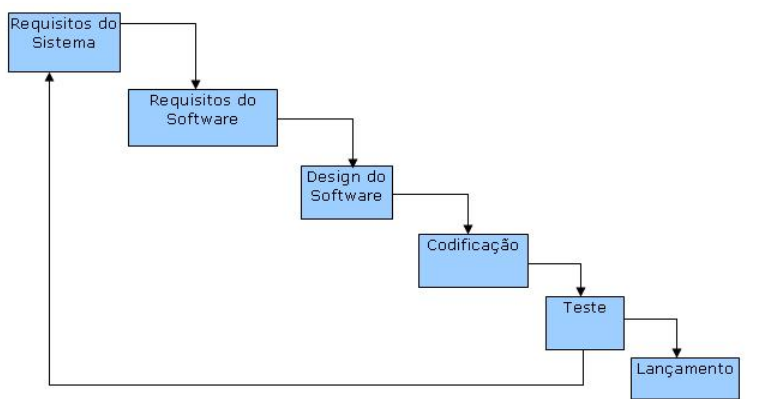

Figura 2 - Fluxograma de desenvolvimento do software de controle do sistema.

Durante a etapa de requisitos do sistema, são levantadas as necessidades que todo o sistema possui. No caso do presente projeto, foi avaliada a necessidade existente de um software que controle o jogo de acordo com os sinais criados pelo EMG System $\AA$. Logo, nos os requisitos do software se pode destacar a necessidade de um sistema de interface simples e intuitiva, o que foi realizado durante a etapa de design do software. Com isso foi possível a codificação do sistema, e por fim foram efetuados testes para validação do controle de cor e intensidade da lâmpada, que é o objetivo principal do software finalizado.

\section{Resultados}

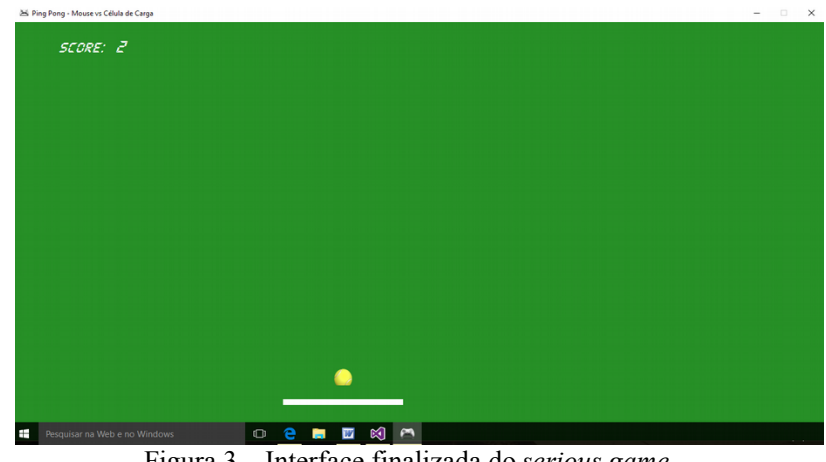

Figura 3 - Interface finalizada do serious game.

O serious game foi desenvolvido e testado com sucesso. Sua interface se tornou intuitiva e simples, (Figura 3) conforme sugestões da International Game Developers Association [7]. A velocidade da bola é controlada pela intensidade da força aplicada na célula de carga, e o controle da raquete é feito pelo mouse do computador.

\section{Discussão}

A interface inicial do jogo foi desenvolvida visando clareza e objetividade para os usuários. Testes foram realizados para garantir a eficiência e eficácia do projeto.

O software foi avaliado como amigável pelos usuários, de fácil utilização. Entretanto, por possuir funções simples, o jogo pode receber futuramente maiores atualizações e funcionalidade extra com funções direcionadas a determinados movimentos em

\section{Conclusão}

O presente projeto foi executado com sucesso, possibilitando a criação de um novo serious game com objetivo de auxiliar na reabilitação dos membros superiores de pacientes fisioterápicos. Também pode ser utilizado em inúmeros estudos e pesquisas com variáveis que trabalham com estudos de musculatura dos membros superiores.

\section{Agradecimentos}

Ao Professor Doutor Adriano de Oliveira Andrade, $\mathrm{PhD}$; pela orientação, apoio e confiança.

\section{Referências}

[1] Marc Prensky. Digital Game-Based Learning. McGraw-Hill. 2001.

[2] Revista Panorama Hospitalar. Game Promete Auxiliar no Tratamento de Pacientes com AVC. 03 de Dezembro de 2014.

[3] Lia Mara Wibelinger et al. Efeitos da utilização do videogame Nintendo Wii como instrumento terapêutico. EFDeportes.com, Revista Digital. Buenos Aires. Ano 17. no 178. Março de 2013.

[4] João Bertolino de S N. O fluxo em jogo sério desenvolvido para reabilitação de membros superiores. Programa de Pós-Graduação em Engenharia Elétrica e de Computação. Escola de Engenharia Elétrica, Mecânica e de Computação. Universidade Federal de Goiás. Goiânia, 2015.

[5] EMG System ${ }^{\circledR}$. < Disponíve l e m : www.emgsystem.com.br, Acesso: 30/06/2016, ás $19 \mathrm{~h} 00 \mathrm{~min}>$

[6] Roger S Pressman. Engenharia de Software. Uma abordagem professional. Bookman Editora. 2011.

[7] International Game Developers Association. $<$ Disponível em: http://www.igda.org/, acesso ás $21 \mathrm{~h} 25 \mathrm{~min}$ em 29 de Junho de 2016>. 